\title{
Propuesta metodológica para la evaluación de áreas afectadas por incendios mediante el uso de imágenes satelitales (Sierra de la Ventana, Argentina) ${ }^{1}$
}

\author{
María Paula Michalijos ${ }^{2}$ y Julio Uboldi ${ }^{3}$
}

\begin{abstract}
RESUMEN
El área de estudio incluye el Parque Provincial Ernesto Tornquist localizado en el sector de Sierra de La Ventana (provincia de Buenos Aires). El objetivo del trabajo es desarrollar una metodología para la delimitación y cálculo de áreas afectadas por incendios, basada en el análisis digital y visual de imágenes satelitales (previa y posterior al incendio) empleando un procesador de imágenes y la elaboración de cartografía temática. Se propone la aplicación de dos índices espectrales, uno de vegetación y otro de áreas quemadas y dos clasificaciones supervisadas. Como resultado se obtuvo que el Índice de Área Quemada (IAQ) es la técnica que ofrece el mejor resultado, permitiendo la delimitación y cálculo de la zona quemada y la discriminación de islas de vegetación no afectadas por el fuego dentro del área analizada. Además se estableció que la vegetación afectada por el incendio correspondió a coníferas y pastizal pampeano.
\end{abstract}

Palabras clave: Teledetección, índices espectrales, clasificación supervisada, incendios.

\begin{abstract}
The study area includes Ernesto Tornquist Provincial Park located in the area of Sierra de La Ventana (Buenos Aires). The aim of this work is to develop a methodology for defining and calculating fire-affected areas, based on visual and digital analysis of satellite imagery (pre and a post fire) using an image processor and the construction of thematic maps, using GIS. We propose the application of two spectral indices, one for vegetation and another for burned areas, and two supervised classifications. Results demonstrated that the Burned Area Index is the technique that provides the best results, allowing the delimitation and calculation of burned areas as well as the discrimination of islands of vegetation not affected by fire within the burned area. Moreover, it was established that the vegetation affected by the fire corresponded to conifers and native grasslands.
\end{abstract}

Key words: Remote sensing, spectral indices, supervised classification, fires.

\footnotetext{
1 Los autores agradecen a la Dra. Vanesa Bohn por su colaboración en el análisis de imágenes satelitales, al personal del Parque Provincial Ernesto Tornquist por la información brindada, a la Comisión Nacional de Actividades Espaciales (CONAE) y al Instituto Nacional de Pesquisas Espaciais (INPE) por facilitar las imágenes satelitales estudiadas. Artículo recibido
}

el 8 de marzo de 2012, aceptado el 3 de septiembre de 2012 y corregido el 2 de abril de 2013.

2 Departamento de Geografía y Turismo, Universidad Nacional del Sur (Argentina).

E-mail:mpmichalijos@uns.edu.ar

3 Departamento de Geografía y Turismo, Universidad Nacional del Sur (Argentina).

E-mail: juboldi@criba.edu.ar 
El fuego es un agente natural de cambios sobre el paisaje e interviene en el mantenimiento y evolución de los ecosistemas. El hombre al modificar el espacio, ha alterado el ciclo natural de incendios, y en ocasiones adquieren dimensiones dramáticas al afectar económicamente su patrimonio. Por eso es necesario contar con información precisa de cada evento, si bien los organismos públicos llevan estadísticas oficiales, los incendios no se referencian geográficamente, ignorándose su exacta dimensión. En los últimos años se han adquirido sistemas de posicionamiento global (GPS), pero su delimitación se restringe al perímetro quemado, sin incluir las manchas interiores.

Hoy en día la teledetección se plantea como una alternativa confiable para cartografiar y evaluar áreas quemadas, ya que permite una observación sistemática de toda la superficie y ofrece información espectral sensible a la discriminación de la señal quemada. (Heredia, 2003), permitiendo además el análisis multiespectral del sector afectado.

En este contexto, en España se realizan numerosas investigaciones al respecto, Martin y Chuvieco (2001) proponen un nuevo índice para cartografiar áreas quemadas, el IAQ (Índice de Áreas Quemadas) utilizando imágenes NOAA-AVHRR y Landsat-TM en grandes incendios en la Península Ibérica. Heredia et al. (2003) comparan distinto índices espectrales (Índice de Vegetación Normalizado, IAQ y Normalized Burnt Ratio) y un análisis de Componentes Principales (ACP) para discriminar áreas quemadas en el Sudoeste de Madrid con imágenes Landsat-TM.

Opazo y Chuvieco (2009) aplican el NBR y el BAI (Burn Area Index) en imágenes MODIS en Colombia. De Santis y Vaughan (2009) trabajan con NDVI, GEMI (Global Environmental Monitoring Index), IAQ, SAVI (Soil Adjusted Vegetation Index) a través de técnicas unitemporales y multitemporales a partir de imágenes Landsat-TM y ETM en Guadalajara. Por último Gajardo et al. (2009) aplicaron en la región del Maule el NDVI, BAI, RATIO y ALME (Análisis Lineal de Mezclas Espectrales).

En el área de estudio no se han realizado trabajos en la temática, los cuales son de gran importancia debido a que en el Parque Provincial Ernesto Tornquist (sudoeste de la provincia de Buenos Aires), todos los años se registran incendios de diferente magnitud. En la reserva se desarrolla una intensa actividad turística que se concentra en el periodo estival, cuando se registran las mayores temperaturas y los vientos son altamente deshidratantes y aumentan en frecuencia e intensidad, en consecuencia es la época de mayor ocurrencia de incendios.

Por otro lado, la importancia del área de estudio radica en la gran diversidad vegetal y en la elevada concentración de especies endémicas, por lo que la reserva ha sido incluida entre las Áreas Valiosas de Pastizal (AVPs) identificadas para Argentina, Uruguay y sur de Brasil (Bilenca y Miñarro, 2004). El área serrana de Ventania concentra el mayor porcentaje de especies de plantas vasculares con mayor prioridad de conservación en la provincia de Buenos Aires.

El objetivo del trabajo es desarrollar una metodología para la delimitación y cálculo de áreas afectadas por incendios, para ello primero se caracteriza el área de estudio, luego se definen los materiales y la metodología a utilizar basados en el análisis digital y visual de imágenes satelitales utilizando un procesador de imágenes y la elaboración de cartografía temática a través de un Sistema de Información Geográfica. Para lo cual se propone la utilización de una imagen posterior al incendio sobre la que se aplican dos índices espectrales y una clasificación supervisada. Luego una vez delimitada el área de interés, y a partir de una imagen previa al incendio, se elabora una clasificación supervisada para evaluar la vegetación afectada. Finalmente se exponen los resultados obtenidos para cada técnica.

\section{Caracterización del área de estudio}

El área de estudio abarca un sector dentro del Parque Provincial Ernesto Tornquist (PPET) (Figura $\mathrm{N}^{\circ}$ 1). La reserva, de 6.000 ha aproximadamente, está ubicada en el partido de Tornquist (provincia de Buenos Aires), sobre la ruta provincial $N^{\circ} 76(\mathrm{~km} \mathrm{225)}$, e integra el Sistema de Áreas Protegidas de la provincia 
de Buenos Aires, una de las pocas reservas naturales de la región pampeana destinada a la conservación de los últimos relictos de pastizal (Torres et al., 2008). La zona constituye uno de los ambientes de mayor calidad ambiental y paisajística de la provincia por lo que posee un gran atractivo, se encuentra dentro del corredor turístico denominado Comarca Serrana, cercano a las localidades de Tornquist, La Gruta, Villa Ventana y Sierra de la Ventana, donde se desarrolla una intensa y creciente actividad turística acompañada de una importante infraestructura y equipamiento. El turismo es la principal actividad económica (Ladeuix, 2008).

La reserva recibió en 2010, 81.106 visitantes (estadísticas anuales de visitantes del PPET). La temporada alta se inicia a mediados de diciembre y se extiende hasta Semana Santa y en los meses de octubre y noviembre cuando se reciben grupos escolares.

El relieve está determinado por el sistema de las Sierras Australes de la provincia de Buenos Aires, conjunto de elevaciones bien definidas, en sentido noroeste-sudeste, de $175 \mathrm{~km}$ de longitud y una anchura máxima de 50 km (Harrington, 1947). En el área de estudio se encuentra el cerro Ventana de 1.134 m.s.n.m., principal atractivo del parque, declarado monumento natural según Ley
11.750/59, por su particular conformación geológica y belleza escénica.

El clima de la región, según la clasificación de Thornthwaite, es subhúmedo seco (C1). La temperatura media en el verano es de $20^{\circ} \mathrm{C}$, con máximas absolutas de $35^{\circ} \mathrm{C}$ a $40^{\circ} \mathrm{C}$. En invierno la temperatura media es de $8^{\circ} \mathrm{C}$ y la mínima absoluta puede descender hasta los $-10^{\circ} \mathrm{C}$, produciéndose heladas y nevadas ocasionales (Gil y Campo, 2000).

La precipitación media anual es de 610 $\mathrm{mm}$, con una gran variabilidad de los valores medios, con una máxima de $1.056 \mathrm{~mm}$ y mínima de 396 mm. Las Iluvias se concentran en los meses de octubre a marzo, con el $63,7 \%$ del total anual. Sin embargo en marzo y en abril se registran los valores mensuales más altos, con 283 mm y 204 mm, respectivamente. El período de bajas precipitaciones corresponde a los meses de junio, julio y agosto con un valor acumulado de $14 \%$ del total (Gil y Campo, 2000).

Los vientos predominantes son del noroeste, altamente deshidratantes, que ocasionan violentos descensos de la humedad relativa, que han alcanzado valores de descenso del $72 \%$ en el lapso de 6 horas (Ramos y Ramos, 2000, citado en Casado, 2006), Ios menos frecuentes son del este y oeste. En

Figura $\mathrm{N}^{0} 1$

Ubicación del área de estudio

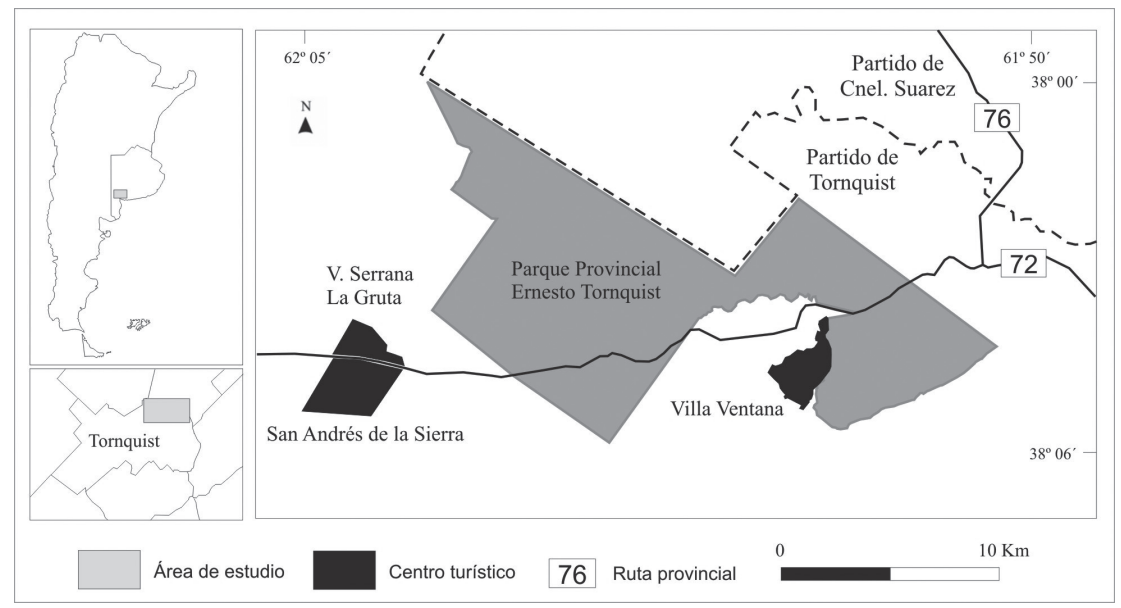

Fuente: Elaboración propia. 
verano se produce la máxima frecuencia e intensidad.

Cabe destacar que la topografía serrana determina variaciones locales (o mesoclimas) del clima regional, en función de la altitud, la exposición y la pendiente (Kristensen y Frangi, 1995). Existe un gradiente altitudinal de temperatura, la cual disminuye $6.9^{\circ} \mathrm{C} / 1.000$ m. (Lizzi et al., 2007).

Según Cabrera, la comarca de la Sierra de la Ventana pertenece a la provincia fitogeográfica Pampeana, distrito Austral. La vegetación está representada por una estepa graminosa con predominio del género Stipa (Flechillas y Paja Vizcachera), Piptochaetium, Fetuca y Briza (Barrera y Frangi, 1997) que están siendo invadidos por especies introducidas de rápida propagación y elevada combustibilidad (cardos, coníferas, eucaliptos y retamas), las que compiten por el nicho ecológico con las nativas.

El sector reúne características que la hacen particularmente valiosa como unidad de conservación, es considerado una isla de bio- diversidad (Kristensen y Frangi, 1995), alberga diecisiete endemismos estrictos y veinte de mayor distribución. Algunos autores consideran que la vegetación de esta zona serrana constituye un distrito fitogeográfico per se.

La temporada de incendios se desarrolla en verano (coincidiendo con la época de mayor afluencia de visitantes), registrándose el $70 \%$ de los eventos en el período 1996-2009 sobre un total de 19. Las causas son diversas, sin embargo predominan los incendios accidentales debido a cigarrillos mal apagado (42\%) y luego naturales, por caída de rayos durante las tormentas (33\%) (Michalijos y Uboldi, 2010).

\section{Materiales y método}

Para el desarrollo de la metodología se analizó el área afectada por el incendio producido el 20 de enero de 2008. Por tal motivo, se seleccionó un sector de la imagen Thematic Mapper del Landsat 5, pathrow 227/086 (provista por CONAE) del 16 de febrero de 2008 (imagen disponible más próxima al día del incendio sin cobertura

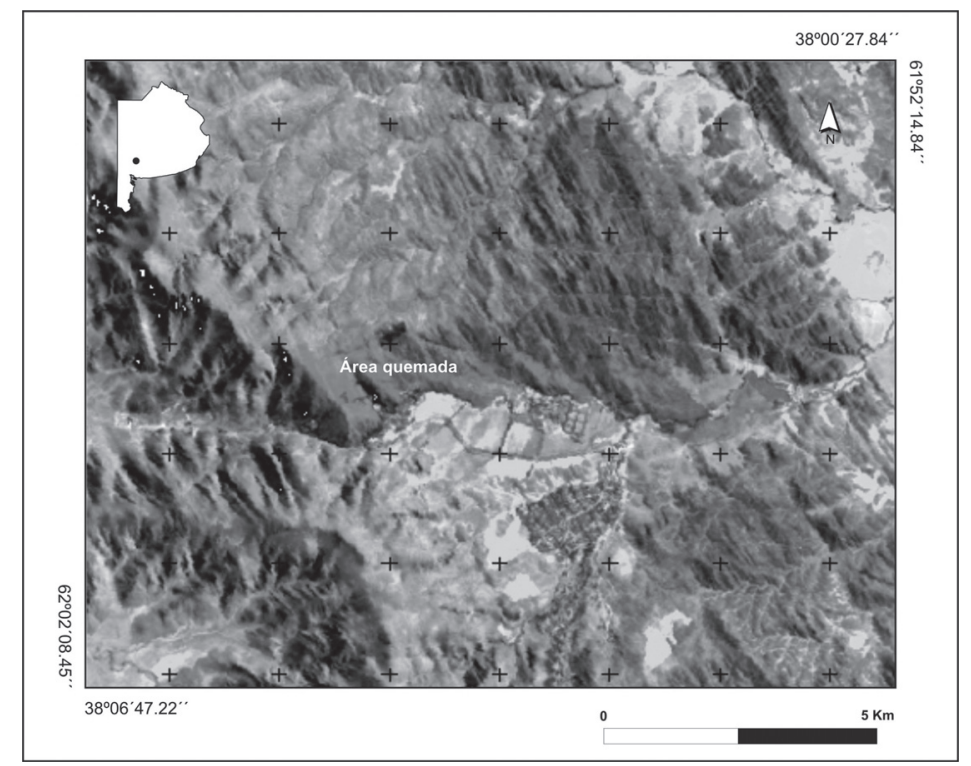

Fuente: Elaboración propia. 
de nubes) (Figura $N^{\circ}$ 2) y un sector de la imagen del 2 de septiembre de 2007 del mismo sensor (provista por INPE, fecha disponible previa, más próxima, al inicio del incendio).

Antes de comenzar a trabajar en el área quemada, fue necesario eliminar las alteraciones en los niveles digitales (ND) de las imágenes satelitales que no sean debido a cambios reales en la cubierta. Para ello se llevó a cabo la corrección radiométrica, utilizando el procesador de imágenes Envi 4.7, donde se transformaron los ND a reflectancia, y de esta manera poder trabajar con variables físicas de significado estándar, comparables en un mismo sensor a lo largo del tiempo o entre lugares. La reflectividad es la relación entre la energía reflejada y la incidente, varía entre 0 y 1 y depende de sus características físicas y químicas y de las condiciones de observación (Chuvieco, 2008).

Luego se realizó la corrección geométrica, proceso por el cual se le asignan coordenadas a la imagen, para importar la cartografía a un SIG y calcular el área quemada. La corrección se realizó a través del establecimiento de puntos de control, tomados a través de un GPS en el campo.

Para la delimitación del área quemada se aplicaron dos índices espectrales, uno de vegetación y otro de áreas quemadas, y una clasificación supervisada, utilizando los procesadores de imágenes Envi 4.7 y PCI 6.2.

El Índice de Vegetación de Diferencia Normalizada (en inglés, NDVI) (1) es una transformación que se realiza para caracterizar las cubiertas vegetales, reforzando la contribución espectral (Pinilla, 1995). Varía entre -1 y 1, cuanto mayor sea el resultado, mayor vigor presenta la vegetación, característica que se traduce en la imagen con colores que van desde los rojos a amarillos y verdes, en contraste con aquellos sectores en los que existe escasa presencia o ausencia total de vegetación, donde los colores van desde los azules a negro.

$$
\begin{aligned}
& \mathrm{NDVI}=\mathrm{IRC}-\mathrm{R} / \mathrm{IRC}+\mathrm{R} \\
& \text { donde IRC= infrarrojo cercano } \mathrm{R}=\text { rojo }
\end{aligned}
$$

El Índice de Área Quemada (IAQ) (2) tiene como objetivo la detección de áreas quemadas en una zona determinada. Se calcula a partir de las bandas del rojo e infrarrojo cercano. Mide la similitud espectral entre cada píxel de la imagen y un punto de convergencia hacia el que tendería una zona quemada, donde domine la señal del carbón. El valor del índice será mayor cuanto menor sea la distancia espectral, es decir, cuanto más similar sea a esa cubierta (Martín, 2001).

$$
\mathrm{IAQ}=1 /\left(\left(\mathrm{R}_{\mathrm{q}}-\mathrm{R}\right)^{2}+\left(\mathrm{IRC}_{\mathrm{q}}-\mathrm{IRC}\right)^{2}\right)(2)
$$

donde IRCq y $\mathrm{Rq}=$ reflectividades de referencia (en el infrarrojo cercano 0.06 y rojo 0.1 ) de una zona quemada conocida.

Si bien el IAQ fue originalmente formulado para ser aplicado a imágenes NOAA-AVH$R R$, también se ha evaluado su capacidad para cartografiar incendios a partir de imágenes Landsat TM, dando resultados positivos (Martín y Chuvieco, 2001).

La clasificación digital implica convertir la imagen multibanda en otra imagen donde los ND de cada pixel no se definen por la radiancia sino por la categoría asignada a ese pixel. La clasificación supervisada se basa en el conocimiento de la zona de estudio, producto de los trabajos de campo realizados, este nivel de referencia permite delimitar sobre la imagen áreas representativas de cada una de las coberturas existentes (definición digital de categorías o fase de entrenamiento), las que se convertirán en las categorías que componen la leyenda a través del agrupamiento de los píxeles de la imagen en cada una de las categorías (fase de asignación) (Chuvieco, 2008). En este caso, las categorías fueron: área quemada, pastizal, cultivos, sierras y pinares y el método utilizado fue el de paralelepípedo.

A partir de la clasificación y de la imagen satelital, se analizó el comportamiento espectral de la categoría correspondiente al área quemada, a fin de comprobar que los sectores delimitados pertenezcan a áreas afectadas por el fuego.

Las imágenes resultantes de la aplicación de los índices (NDVI e IAQ) fueron nuevamente sometidas a una clasificación super- 
visada (método paralelepípedo). Las clases correspondientes al área quemada fueron vectorizadas para la extracción de los polígonos, los que fueron importados en el SIG Arc Gis 9.1 para el cálculo de su superficie (has), y la elaboración de cartografía temática que incluye la delimitación de las áreas.

Por último se realizó, a partir de la imagen del 2 de septiembre de 2007, una clasificación supervisada (método paralelepípedo), con las categorías: pastizal, sierras y pinares, se vectorizaron los resultados para exportarlos al SIG Arc View 9.1 y superponerlos con el área quemada obtenida del IAQ, con el objetivo de establecer el tipo de vegetación afectada.

\section{Índice de Vegetación de Diferencia Normalizada (NDVI)}

Como resultado de la aplicación del NDVI, para la detección de áreas quemadas, se obtuvieron valores mínimos y máximos de -0.08 y 0.57 , respectivamente. Ello indicó vegetación con escaso vigor y en recuperación, evidenciando distintos grados de severidad o daño. Además se pueden observar algunas islas de vegetación que no fueron afectadas por el fuego.

Sin embargo, no fue posible delimitar el área quemada, la imagen analizada corresponde a 24 días posteriores al inicio del incendio, por lo que la vegetación ha co- menzado a recuperarse. Los valores medios y máximos registrados $(0,09$ y 0.57 respectivamente) son los que dificultan el trazado del área, debido a que se confunden con el pastizal que crece en las sierras, cuyos valores oscilan entre 0,22 y 0,56 . (Figura $N^{\circ} 3$ ). Resultados similares obtuvieron Gajardo et al. (2009), Heredia et al. (2003) y De Santis y Vaughan (2009) quienes también manifestaron la confusión, que este índice presenta, entre la señal quemada y otras cubiertas. Demostrando que esta técnica no representa un buen discriminador del área quemada en imágenes posteriores al incendio.

Martín y Chuvieco (2001) expresaron, en su trabajo, los problemas de aplicabilidad de este índice en áreas de escasa vegetación, donde el suelo al descubierto altera notablemente la información que proporciona la cubierta vegetal presente, sin embargo esta aplicación se justifica por su capacidad para discriminar zonas con vegetación de otras cubiertas, así como su utilidad para atenuar la influencia de factores externos.

Posteriormente, se clasificó el NDVI (Figura $\mathrm{N}^{\circ} 4$ ) para extraer el área de interés, estableciendo dos clases: quemado y no quemado. Las muestras se tomaron teniendo en cuenta el valor de los pixeles en sectores donde se tenía la certeza de que la vegetación había sido afectada por el fuego. Al observar la Figura $\mathrm{N}^{\circ} 4$, se puede apreciar

Figura $\mathrm{N}^{\circ} 3$

Aplicación del Índice de Vegetación de Diferencia Normalizada.

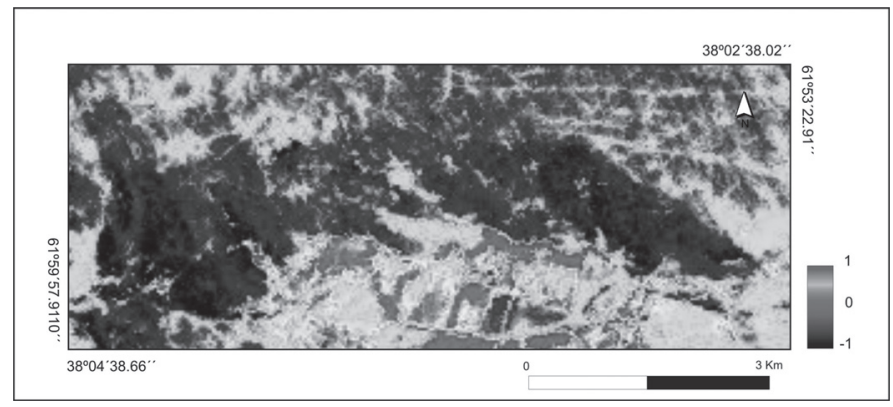

Fuente: Elaboración propia. 


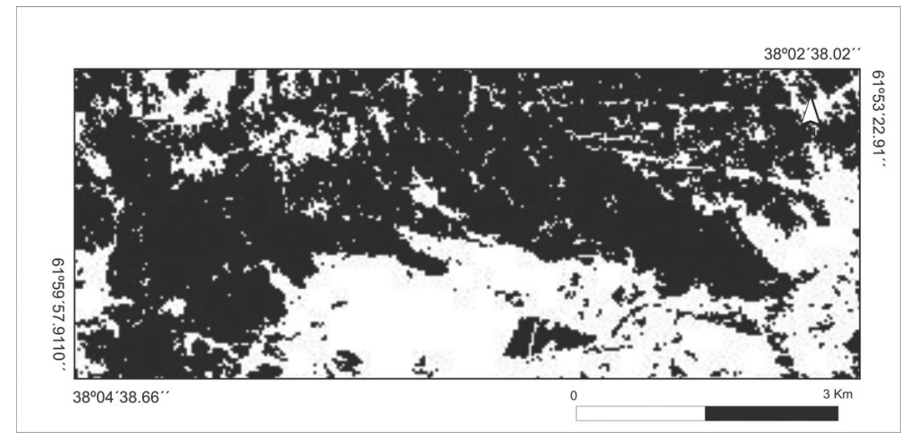

Fuente: Elaboración propia.

la dificultad para delimitar el área quemada, solo el límite sur está claramente definido.

\section{Índice de Área Quemada (IAQ)}

Tras la aplicación del IAQ, fue posible delimitar el área quemada teniendo en cuenta el contraste entre el sector quemado y el resto de las cubiertas. Además se detectaron diferentes grados de severidad e islas de vegetación dentro del área (Figuras $\mathrm{N}^{0} 5$ y $\mathrm{N}^{\circ}$ 6). Resultados similares a los hallados por Martín y Chuvieco (2001), para quienes, este índice presenta una clara capacidad de discriminación frente al NDVI, al GEMI y al SAVI. Sin embargo Heredia et al. (2003), a pesar de encontrar una clara diferenciación interna del área quemada, identificó algunas confusiones entre esta y pequeñas láminas de agua y sombra.

Luego se llevó a cabo la clasificación supervisada del IAQ, donde se establecieron dos clases: quemado y no quemado, a partir de ella se calculó la superficie del área quemada en $683 \mathrm{ha}\left(6,830 \mathrm{~km}^{2}\right)$.

\section{Clasificación Supervisada}

El área delimitada por la clasificación supervisada (Figura $N^{\circ} 7$ ) de la imagen satelital es similar a la resultante de la aplicación del $I A Q$, también dentro de ella se observan islas de vegetación no afectadas por el fuego. Sin

Figura $N^{\circ} 5$

Aplicación del Î́ndice de área quemada

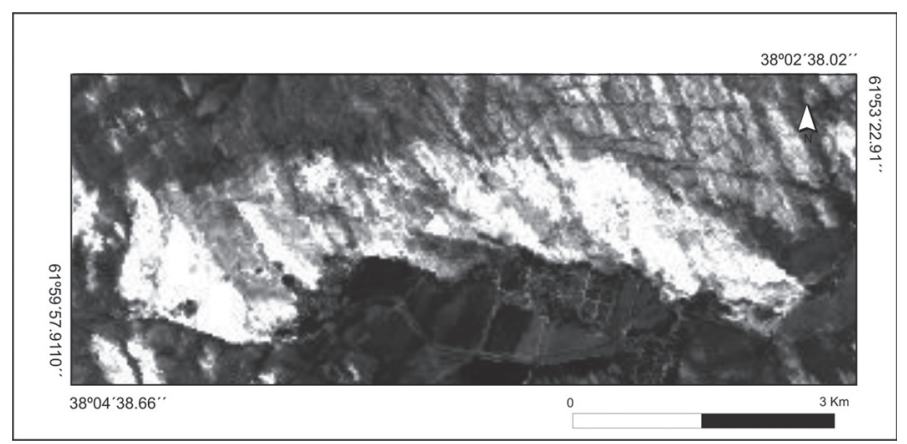

Fuente: Elaboración propia. 
Figura $\mathrm{N}^{\circ} 6$

Aplicación del método de clasificación supervisada sobre el producto IAQ

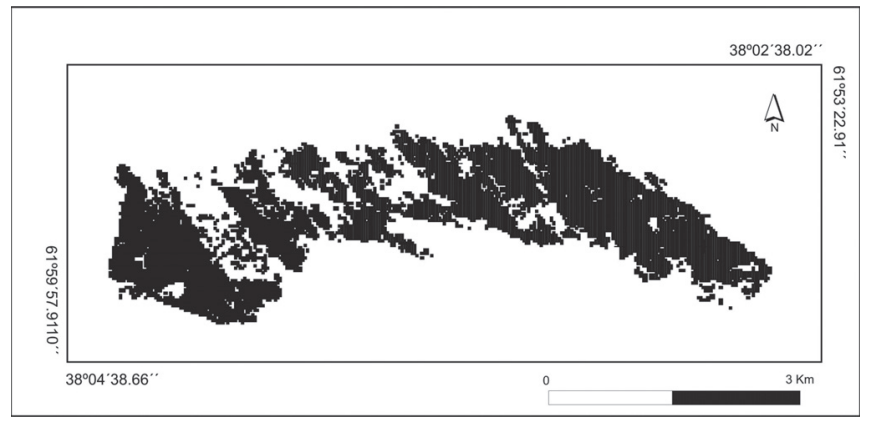

Fuente: Elaboración propia.

embargo, se debe tener en cuenta que, los sectores serranos de escasa vegetación fueron clasificados como áreas quemadas, lo que dificulta la demarcación del área total, sobreestimando la superficie afectada por el fuego.

Por otro lado los sectores correspondientes a pastizal de sierras se clasificaron como pinares y los cultivos son los que presentaron mejores resultados.

Según este método el área cubre 927,8 has $\left(9,278 \mathrm{~km}^{2}\right), 244,8$ ha más que la superficie determinada por el IAQ, es decir que el porcentaje de diferencia entre ambos cálculos es de 26,38\% (Figura № 8).

A partir de la clasificación y de la imagen satelital se coligaron los pixeles de ambas ventanas para obtener los valores medios de reflectancia del área quemada para cada banda (Cuadro No 1 y Figura No 9), y graficar la curva de la vegetación, de esta manera, se asegura que las muestras utilizadas para realizar la clasificación corresponden a sectores afectados por el fuego.

En la curva de vegetación, en las bandas correspondientes al sector visible del espectro electromagnético (bandas 1, 2, y 3), se puede observar una pendiente descendente. En el infrarrojo cercano (banda 4) la reflectividad es baja debido principalmente a la destrucción de la estructura interna de la hoja y a la disminución de la actividad clorofílica. En el infrarrojo medio (banda 5 y 7) los valores fueron elevados por la escasez de agua en la estructura de la planta, producto de la relación negativa entre el contenido de humedad y reflectividad en este sector del espectro electromagnético (Chuvieco, 2008).

Figura $\mathrm{N}^{0} 7$

Aplicación del método de clasificación supervisada

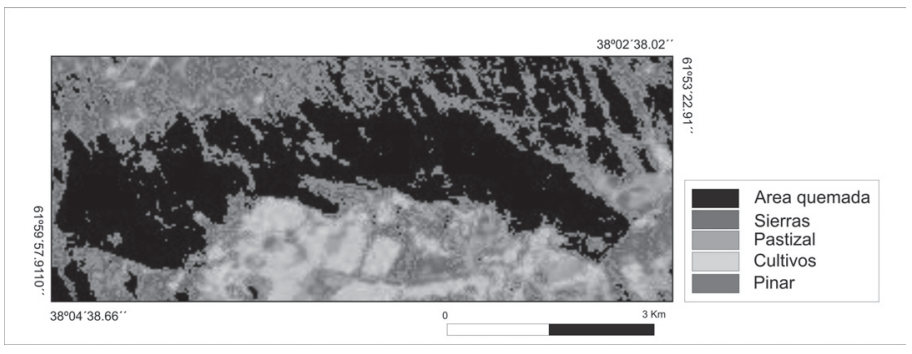

Fuente: Elaboración propia. 
Área quemada calculada a partir de la clasificación supervisada

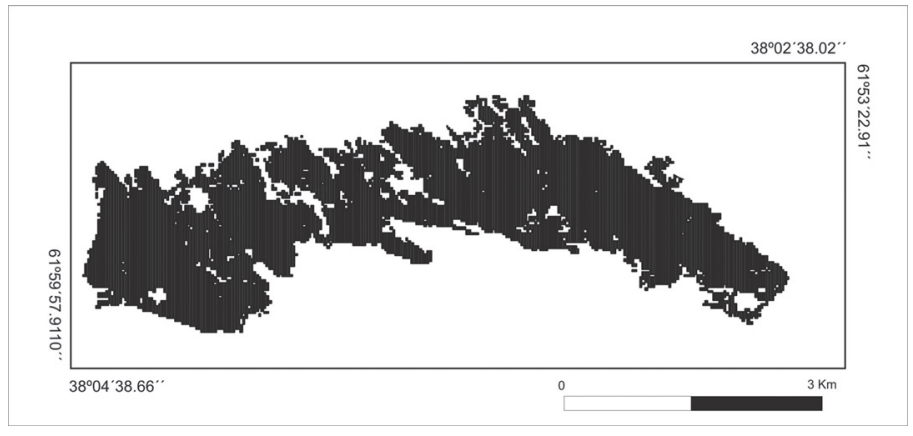

Fuente: Elaboración propia.

Cuadro $N^{\circ} 1$

Valores de reflectancia del área quemada

\begin{tabular}{|l|l|r|}
\hline \multicolumn{2}{|c|}{ Intervalos espectrales del Landsat } & \multicolumn{1}{c|}{$\begin{array}{c}\text { Valores de } \\
\text { reflectancia }\end{array}$} \\
\hline Banda 1 & Azul $(0,45-0,52 \mathrm{~mm})$ & 0,073694 \\
\hline Banda 2 & Verde $(0 ., 52-0,60 \mathrm{~mm})$ & 0,065659 \\
\hline Banda 3 & Rojo $(0 ., 63-0,69 \mathrm{~mm})$ & 0,057434 \\
\hline Banda 4 & $\begin{array}{l}\text { Infrarrojo cercano }(0,16- \\
\text { 0,90 mm })\end{array}$ & 0,143182 \\
\hline Banda 5 & Medio $(1,55-1,75 \mathrm{~mm})$ & 0,167348 \\
\hline Banda 7 & Medio $(2,08-2,35 \mathrm{~mm})$ & 0,135747 \\
\hline
\end{tabular}

Fuente: Elaboración propia.

\section{Figura $N^{\circ} 9$}

Curva espectral de vegetación afectada por el fuego obtenida a partir de los valores de reflectancia del área quemada.

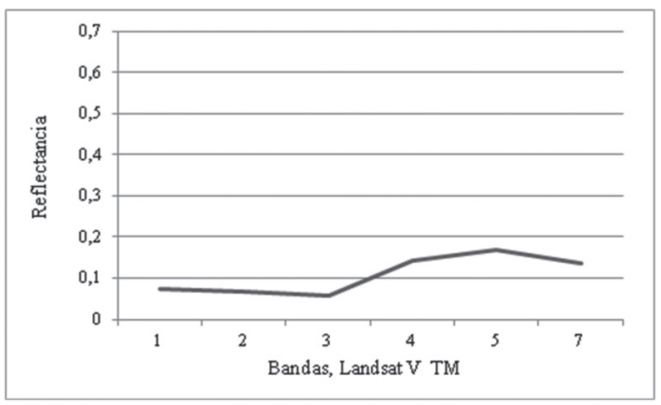

Fuente: Elaboración propia.

\section{Comparación de los métodos utilizados}

Al comparar los resultados del NDVI, del IAQ y de la clasificación supervisada, se obtuvo que el método que resulta más conveniente para cartografiar áreas quemadas es la aplicación del IAQ, permitiendo una clara discriminación entre quemado y no quemado, mientras que el NDVI y la Clasificación presentan diversas confusiones con otras coberturas, sobreestimando la superficie quemada total.

La dificultad que presentó el NDVI se debe a la distancia entre la fecha de la imagen y la del incendio. Pasados 24 días el pastizal ha comenzado a recuperarse, debido a que las gramíneas poseen respuestas morfológicas (xilopodios, tallos subterráneos) y funcionales específicas (alta capacidad de rebrote) que les permiten rebrotar fácilmente transcurrido el incendio (Barrera y Frangi, 1997). De esta manera la señal de la vegetación fue influenciada por la presencia del pastizal de las sierras. Además las áreas quemadas presentan diversos grados de intensidad, lo que dificulta establecer fronteras nítidas entre lo afectado y no afectado por el fuego.

Con respecto a la clasificación, se observaron errores de comisión, es decir, que se reconocieron pixeles quemados cuando no fueron afectados por el fuego, situación que se dio no solo dentro del área de interés sino en toda la imagen. Como se mencio- 
nó anteriormente, los sectores de escasa vegetación fueron clasificados como áreas quemadas.

Clasificación supervisada sobre la imagen del 2 de septiembre de 2007

$\mathrm{Al}$ área quemada delimitada por el IAQ se le superpuso la clasificación supervisada de la imagen previa al incendio, con el objetivo de establecer el tipo de vegetación afectada por el fuego (Figura $N^{\circ} 10$ ).

En el Cuadro $N^{\circ} 2$ se detallan la cantidad de hectáreas de cada cobertura clasificada, en ella se puede observar que la vegetación más afectada por el incendio son las coníferas con 189.22 ha y luego el pastizal (93.42 ha), la categoría sin clasificar pertenece a las sombras proyectadas por las sierras.

Cabe destacar que las coníferas (excepto el cedro y el ciprés), como se mencionó anteriormente, pueden considerarse invasoras dentro del parque, por tener poblaciones autorregenerativas, es decir, que pueden reproducirse exitosamente a partir de un incendio y reemplazar a los árboles viejos con renovales. El fuego parece ser un factor desencadenante de la rápida expansión que han sufrido dichas especies, favoreciendo la liberación de semillas de los conos de los pinos adultos y reduciendo la capacidad competitiva del pastizal (Zalba y Cazzaniga, 2002). Situación que compromete a los objetivos de conservación del pastizal pampeano de la reserva.

Figura $\mathrm{N}^{\circ} 10$

Coberturas afectadas por el incendio obtenidas a partir de la clasificación supervisada de 2007 y del área quemada delimitada por el IAQ.

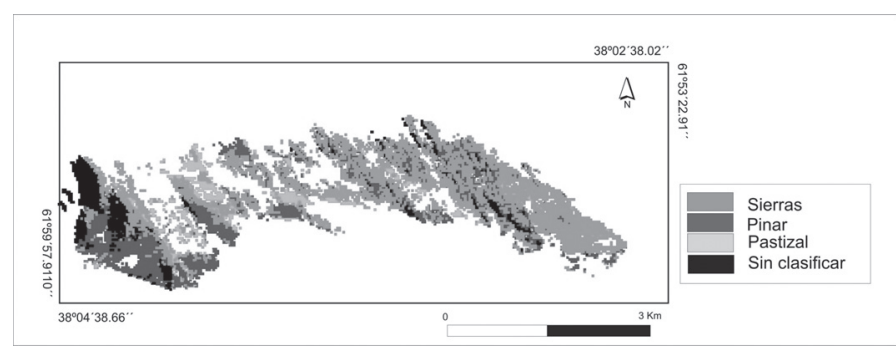

Fuente: Elaboración propia.

Cuadro $\mathrm{N}^{\circ} 2$

Superficies afectadas por el incendio según coberturas obtenidas a partir de la clasificación digital supervisada de 2007

\begin{tabular}{|c|c|}
\hline Cobertura & Sup. Quemada en ha \\
\hline Sierras & 351,87 \\
\hline Pinar & 189,22 \\
\hline Pastizal & 93,42 \\
\hline Sin clasificar & 48,49 \\
\hline Total & 683 \\
\hline
\end{tabular}

Fuente: Elaboración propia.

\section{Conclusiones}

Como resultado de la aplicación de la metodología propuesta, se puede concluir que, para analizar áreas quemadas, en un sector serrano de clima templado con vegetación de pastizal, a escala media, es apropiada la utilización de imágenes satelitales Landsat 5, TM, debido a su resolución temporal (16 días), espacial (30 metros) y radiométrica (bandas en el visible, infrarrojo cercano y medio).

El procesamiento digital de imágenes satelitales permite elaborar información derivada de las bandas originales, resaltando determinados tipos de cobertura, en nuestro caso 
particular las áreas afectadas por incendios, las que son posibles discriminar con precisión en función de la respuesta espectral de la vegetación quemada.

Los resultados obtenidos demostraron que el NDVI presentó dificultades para delimitar el área quemada, debido a la distancia entre la fecha del incendio y de la toma de la imagen, motivo por el cual no se pudo obtener la superficie afectada por el fuego.

La clasificación supervisada delimitó y calculó el área de interés en 927,8 ha, un $26,38 \%$ más que el IAQ (683 ha), por la semejanza espectral entre la escasa vegetación que crece en las sierras y la afectada por el fuego, es decir que, el IAQ es el producto que mejor se ajusta al área de estudio, al diferenciar ambas señales pudiendo no solo delimitar el área quemada, sino también distinguir islas de vegetación no afectadas por el fuego.

La clasificación supervisada de la imagen del 2 de septiembre de 2007 permitió establecer el tipo de vegetación afectada. Las coníferas totalizaron 189,22 ha y el Pastizal 93,42 ha.

\section{Referencias bibliográficas}

BARRERA, M. y FRANGI, J. Modelo de estados y transiciones de la arbustificación de pastizales de Sierra de la Ventana, Argentina. Ecotrópico, 1997, № 10, p. 161-166.

BILENCA, D. y MIÑARRO, F. Identificación de áreas valiosas de pastizal (AVPs) en las pampas y campos de Argentina, Uruguay y sur de Brasil. Buenos Aires: Fundación Vida Silvestre Argentina, 2004.

CABRERA, A. Fitogeografía de la Argentina. Boletín de la Sociedad Argentina de Botánica, 1971, XIV, p. 1-42.

CASADO, A.L. Modelo digital para la prevención de incendios forestales en el área de Villa Ventana. Bahía Blanca: Argentina Universidad Nacional del Sur, 2006.

CHUVIECO, E. Teledetección ambiental. La observación de la tierra desde el espacio. Barcelona: Ariel ciencia, 2008.
DE SANTIS, A. y VAUGHAN, P. Revisión de las técnicas de identificación cartográfica de áreas quemadas. Recursos Rurais, 2009, No 5, p. 93-100.

GAJARDO, J.; MENA, C.; ORMAZÁBAL, Y. y MORALES, Y. Cartografía local de áreas quemadas empleando teledetección. $4^{\circ}$ Congreso Chileno de Ciencias Forestales, 2009, p. 1-19.

GIL, V. y CAMPO DE FERRERAS, A. Cuenca del arroyo del Oro: Características hidrográficas y los efectos sobre la población. Actas III Jornadas de Geografía Física, 2000, p.153-159.

HARRINGTON, H. Explicación de las cartas geológicas $33 \mathrm{~m}$ (Sierra de Cura Malal) y $34 \mathrm{~m}$ (Sierra de la Ventana). Prov. Bs.As. Dirección de Minería y Geología, 1947, Vol. 61, p. 43.

HEREDIA LACLAUSTRA, A.; MARTÍNEZ SÁNCHEZ, S.; QUINTERO, E.; PIÑEROS, W. y CHUVIECO, E. Comparación de distintas técnicas de análisis digital para la cartografía de áreas quemadas con imágenes LANDSAT ETM+. GeoFocus, 2003, Nº 3, p. 216-234.

KRISTENSEN, J. y FRANGI, J. La Sierra de la Ventana: una isla de biodiversidad. Ciencia Hoy, 1995, No 30, p. 25-30.

LADEUIX, N. Impacto de la actividad turística en Villa Ventana. Efectos sobre la sostenibilidad ambiental. Bahía Blanca: Universidad Nacional del Sur, 2008.

LIZZI, J.M.; GARBULSKY, M.; GOLLUSCIO, R. y DEREGIBUS, A. Mapeo indirecto de vegetación de Sierra de la Ventana, provincia de Buenos Aires. Ecologia Austral, 2007, No 17 , p. 217-230.

MARTIN, M.P. y CHUVIECO, E. Propuesta de un nuevo índice para cartografía de áreas quemadas: aplicación a imágenes NOAAAVHRR y Landsat-TM. Revista de Teledetección, 2001, Nº 16, p. 57-64.

MICHALIJOS, M.P. y UBOLDI, J. Caracterización del régimen de fuego en el Parque Provincial Ernesto Tornquist, provincia de Buenos Aires. I Jornadas de las nuevas tec- 
nologías de la información geográfica del sur argentino, 2010, p. 225-235.

OPAZO, S. y CHUVIECO, E. Cartografía de áreas quemadas en Sudamérica: detección de píxeles semilla. Revista de Teledetección, 2009, No 32 , p. 50-71.

PINILLA RUIZ, C. Elementos de Teledetección. Madrid: RA-MA, 1995.

RAMOS, P. y RAMOS, F. Algunas sugerencias para la conservación de espacios verdes en la comarca serrana de Villa Ventana. Argentina: Editorial Universitaria de La Plata, 2000.
TORRES, Y.A.; LONG, M.A. y ZALBA, S.M. Caracterización de los ambientes asociados a poblaciones naturales de Pavonia cymbalaria (Malvaceae) en pastizales de Sierra de la Ventana (Buenos Aires). FYTON. Revista Internacional de Botánica Experimental, 2008, No 77 , p. 225-240.

ZALBA, S. y CAZZANIGA, N. Forestación en el Parque Provincial Ernesto Tornquist: cuando los árboles son en problema. II Jornadas Interdisciplinarias del Sudoeste Bonaerense, 2002, p. 503-515. 